\title{
EVALUATION OF RUTHENIUM-BEARING SINGLE CRYSTAL SUPERALLOYS - A DESIGN OF EXPERIMENTS
}

\author{
R.A. Hobbs ${ }^{1}$, G.J. Brewster ${ }^{2}$, C.M.F. Rae ${ }^{2}$ and S. $\operatorname{Tin}^{3}$ \\ ${ }^{1}$ Rolls-Royce plc, PO Box 31, Derby DE24 8BJ, UK \\ ${ }^{2}$ Department of Materials Science \& Metallurgy, University of Cambridge, Pembroke Street, Cambridge CB2 3QZ, UK \\ 3Department of Mechanical, Materials \& Aerospace Engineering, Illinois Institute of Technology, 10W. $32^{\text {nd }}$ Street,
} Chicago, IL 60616, USA

Keywords: Single Crystal, Ruthenium (Ru), Creep, Lattice Misfit, Rafting, Fatigue, Oxidation, TBC

\begin{abstract}
Eight Ru-containing single crystal Ni-base superalloys were devised and evaluated using a design of experiments approach to isolate the effects of four elements, namely $\mathrm{Co}, \mathrm{Mo}, \mathrm{W}$ and $\mathrm{Ru}$, on creep, plain low-cycle fatigue (LCF), $1100^{\circ} \mathrm{C}$ cyclic oxidation and thermal barrier coating (TBC) compatibility. All the alloys compared favourably to CMSX-4 mechanically, however, they underperformed in oxidation. Mo and Co were found to adversely affect both the cyclic oxidation performance and TBC compatibility. None of the four factorials were found to have a statistically significant impact on LCF. In general, the largest creep temperature benefits over CMSX-4 were observed at low $\left(<800^{\circ} \mathrm{C}\right)$ and high $\left(>1000^{\circ} \mathrm{C}\right)$ temperatures. At intermediate temperatures $\left(\sim 850^{\circ} \mathrm{C}\right.$ to $\left.950^{\circ} \mathrm{C}\right)$ the improvement in temperature capability was less pronounced. Mo was found to have the only statistically significant contribution on creep. Consistent with the correlation between lattice misfit and creep, the impact was positive at low temperatures/high stresses and negative at intermediate conditions. As misfit increases in low temperature creep the density of dislocations in the $\gamma^{\prime}$ decreases and the number of stacking faults in the $\gamma$ channels increases. The latter culminates in a negative misfit threshold above which primary creep is effectively 'turned off'. Under intermediate creep conditions, high negative misfit alloys spontaneously develop a 'labyrinth' structure that comprises approximately equal numbers of rafts in all three $<001>$ directions irrespective of the direction of the applied stress. This tendency for labyrinth rafting imposes an upper limit on the magnitude of the negative misfit and thus the degree to which the $\gamma$-matrix can be usefully strengthened with refractory elements at intermediate temperatures.
\end{abstract}

\section{Introduction}

High fuel costs and increasing environmental pressures demand unprecedented and ambitious performance, efficiency and emission targets from the next generation of gas turbine engines. The development of more temperature resistant single crystal Nibase superalloys for turbine blade applications is critical to the delivery of this technology. Significant temperature benefits over the current generation of alloys by manipulation of the existing constituent elements are limited by microstructural instability, density and processing difficulties. Consequently, novel elemental additions, such as ruthenium $(\mathrm{Ru})$, are being investigated because it directly addresses issues associated with long-term microstructural instabilities in high refractory content alloys [1-4].
This improvement in stability not only extends the creep capability of single crystal superalloys to higher temperatures $[5,6]$ but it also allows a more holistic approach to alloy design, where the relative concentrations of the existing constituents are tailored to achieve a balanced alloy that more adequately satisfies the long list of turbine blade material requirements, not simply that of creep temperature capability. However, to develop a balanced alloy a greater understanding of individual elemental effects and optimal composition ranges is required.

\section{Experimental Procedure}

Eight Ru-containing single crystal Ni-base superalloys, designated LDSX, were devised using a design of experiments (DoE) approach to isolate the effects of four elements, namely Co, Mo, $\mathrm{W}$ and $\mathrm{Ru}$, on the mechanical and environmental properties investigated, Table I. Consequently, the concentrations of the other constituents were maintained nominally identical throughout the alloy series. The four elements in the factorial design were assigned two settings/contents: low and high. Co and $\mathrm{Ru}$ were selected to investigate their respective benefits as microstructural stabilising elements with respect to TCP precipitation while Mo and $\mathrm{W}$ were selected to elucidate their relative strengthening benefits and impact on microstructural stability. Eight alloys were defined, as this is the minimum number required to isolate the primary effects of four variables in a factorial DoE. Note that LDSX-1 and LDSX-8 are the least and most highly alloyed variants respectively.

All alloys were cast into $<001>$ oriented single crystal test bars at the Precision Casting Facility (PCF) in Derby, England, and subjected to identical solution heat treatments of $1340^{\circ} \mathrm{C}$ for $10 \mathrm{hrs}$ save LDSX-3 and LDSX-8, which were soaked at peak temperature for an additional 10 and 5 hrs respectively due to their inherent microstructural instability, and LDSX-1, which was solutioned $15^{\circ} \mathrm{C}$ higher because of its higher $\gamma^{\prime}$ solvus. All alloys were subsequently primary and secondary aged at $1150^{\circ} \mathrm{C} / 4 \mathrm{hrs}$ and $870^{\circ} \mathrm{C} / 16 \mathrm{hrs}$ respectively.

The alloys were tested in creep, low-cycle fatigue (LCF), high temperature cyclic oxidation and thermal barrier coating (TBC) compatibility. All data from the DoE were statistically analysed using MINITAB 14 to ascertain the statistical significance and relative impacts of each of the four factorials on the property in question. 
Table I Nominal alloy compositions in wt.\%.

\begin{tabular}{cccccccccccc}
\hline Alloy & Ni & Al & Co & Cr & Mo & Ti & Ta & W & Re & Ru & Hf \\
\hline LDSX-1 & Bal. & 6.0 & 3.0 & 3.0 & 2.5 & 0.25 & 6.5 & 2.9 & 6.2 & 3.5 & 0.1 \\
LDSX-2 & Bal. & 6.0 & 8.0 & 3.0 & 5.0 & 0.25 & 6.5 & 2.9 & 6.2 & 3.5 & 0.1 \\
LDSX-3 & Bal. & 6.0 & 3.0 & 3.0 & 5.0 & 0.25 & 6.5 & 4.8 & 6.2 & 3.5 & 0.1 \\
LDSX-4 & Bal. & 6.0 & 8.0 & 3.0 & 2.5 & 0.25 & 6.5 & 4.8 & 6.2 & 3.5 & 0.1 \\
LDSX-5 & Bal. & 6.0 & 8.0 & 3.0 & 2.5 & 0.25 & 6.5 & 2.9 & 6.2 & 5.0 & 0.1 \\
LDSX-6 & Bal. & 6.0 & 3.0 & 3.0 & 2.5 & 0.25 & 6.5 & 4.8 & 6.2 & 5.0 & 0.1 \\
LDSX-7 & Bal. & 6.0 & 3.0 & 3.0 & 5.0 & 0.25 & 6.5 & 2.9 & 6.2 & 5.0 & 0.1 \\
LDSX-8 & Bal. & 6.0 & 8.0 & 3.0 & 5.0 & 0.25 & 6.5 & 4.8 & 6.2 & 5.0 & 0.1 \\
\hline
\end{tabular}

\section{$\underline{\text { Creep }}$}

Tests were conducted to rupture using constant load creep rigs under conditions ranging from $750^{\circ} \mathrm{C} / 800 \mathrm{MPa}$ to $1100^{\circ} \mathrm{C} / 140 \mathrm{MPa}$. The rupture samples were sectioned for microstructural analysis. Sections $0.5 \mathrm{~mm}$ in thickness were taken normal to the loading axis on the (001) plane from which disks $\sim 3 \mathrm{~mm}$ in diameter were spark eroded and subsequently mechanically ground to $\sim 0.1 \mathrm{~mm}$. The disks were then electropolished using a twin-jet polisher with a solution of $10 \%$ perchloric acid in methanol at $\sim-5^{\circ} \mathrm{C}$ and $25 \mathrm{~V}$. The resultant foils were analysed using a JEOL 200CX TEM to compare microstructures, specifically the $\gamma^{\prime}$ morphology, the extent of rafting, the presence of TCPs, the deformation mechanism(s), dislocation spacing, and the phase(s) within which the deformation was concentrated.

The extent and rate of rafting at intermediate temperatures was investigated for three of the alloys covering the spread in the $\gamma-\gamma^{\prime}$ lattice mismatch of the alloys. LDSX-1, LDSX-6 and LDSX-8 were deformed in creep at $950^{\circ} \mathrm{C} / 375 \mathrm{MPa}$ to give a total strain of $0.13 \%, 0.22 \%$ and $0.12 \%$ respectively. The introduction of an anisotropic strain into the matrix is a necessary pre-cursor for the formation of a rafted structure. It has been shown that once that strain reaches a critical value of $\sim 0.1 \%$ rafting continues at the same rate even upon removal of the original stress [7]. This allows the interrupted creep specimen to be dissected and the rafting to be studied by exposing small sections to further isothermal anneals at $950^{\circ} \mathrm{C}$. The rafted samples were cut parallel to the $<010>$ axes and examined in the SEM after additional isothermal exposure times of 10, 50, 100 and 500 hours.

\section{$\underline{\text { Low-Cycle Fatigue }}$}

Six samples per alloy were tested in plain $\mathrm{LCF}$ at $750^{\circ} \mathrm{C}$, a frequency of $0.25 \mathrm{~Hz}$ and $\mathrm{R}=0$ to simulate the load-bearing cold webs in a cooled turbine blade.

\section{High Temperature Cyclic Oxidation}

The bare alloy cyclic oxidation resistance of each alloy was tested in air at $1100^{\circ} \mathrm{C}$. Each cycle comprised a $1 \mathrm{hr}$ soak at peak temperature $\left(>0.97 \mathrm{~T}_{\text {dwell }}\right)$ followed by a $10 \mathrm{~min}$ blast with compressed air in a cooling station. Samples of each alloy, $8 \mathrm{~mm}$ diameter and $50 \mathrm{~mm}$ long in dimension, were exposed to a maximum of 200 cycles. The initial weight and dimensions of the test pieces were measured using a calibrated balance and micrometer and the mass gain/loss was monitored with a balance throughout the test at 5 cycle intervals. Upon completion, the mass gain/loss was converted to specific mass change by normalising the data against the specimen surface area.
Scanning electron microscopy was used for detailed compositional analyses of the oxide species. A Philips XL-30 Field Emission Gun Scanning Electron Microscope (FEGSEM) was operated with an accelerating voltage of $25 \mathrm{kV}$ and working distance of $10 \mathrm{~mm}$. The eDXi software was employed and the raw data was subsequently corrected using the ZAF subroutine.

XRD was performed on the cyclic oxidation samples of each alloy exposed to $\sim 150$ cycles. Measurements were made on a Bruker AXS D8 Advance x-ray diffractometer with a LynxEye detector in standard $\theta / 2 \theta$ Bragg-Brentano operation. Scans were performed over a $2 \theta$ range of $20-90^{\circ}$ with a step size of $0.03^{\circ}$ and a $0.5^{\circ}$ divergent slit. Specimens were rotated during the scan to average over the specimen area.

Thermo gravimetric analysis (TGA) was performed on specimens of both LDSX-1 and LDSX-2 at $1100^{\circ} \mathrm{C}$. TGA was performed on a CI Electronics MK2-M5 thermo gravimetric mass balance, with a sensitivity of $0.1 \mu \mathrm{g}$. Testing was conducted in standing laboratory air, using an open system.

\section{TBC Compatibility}

Samples of each alloy, $12 \mathrm{~mm}$ in diameter and $10 \mathrm{~mm}$ long, were electron beam-physical vapour deposition (EB-PVD) TBC coated following the application of a diffused-platinum low cost bond coat (LCBC). Testing was conducted at $1190^{\circ} \mathrm{C}$; each cycle comprised a $1 \mathrm{hr}$ soak at peak temperature $\left(>0.97 \mathrm{~T}_{\mathrm{dwell}}\right)$ followed by a $10 \mathrm{~min}$ blast with compressed air in a cooling station, up to a maximum of 150 cycles. Failure was defined by $20 \%$ spallation of the TBC.

\section{Results and Discussion}

\section{Creep}

The times to $1 \%$ creep strain for the LDSX alloys are plotted relative to CMSX-4 in the form of a Larson-Miller diagram in Figure 1. In general, the largest improvements in creep performance over CMSX-4 were observed at low temperatures $\left(<800^{\circ} \mathrm{C}\right) /$ high stresses and high temperatures $\left(>1000^{\circ} \mathrm{C}\right) /$ low stresses. At intermediate temperatures $\left(850^{\circ} \mathrm{C}\right.$ to $\left.950^{\circ} \mathrm{C}\right)$ and stresses, however, the improvement in creep performance is less pronounced. These trends are highlighted by the plot of temperature benefit of the LDSX alloys to $1 \%$ creep strain over CMSX-4 as a function of test temperature in Figure 2. Moreover, both Figures 1 and 2 clearly illustrate that, despite significant variations in creep performance with chemistry at low and high test temperatures, under intermediate conditions the creep performance of all the experimental fourth-generation alloys tends 


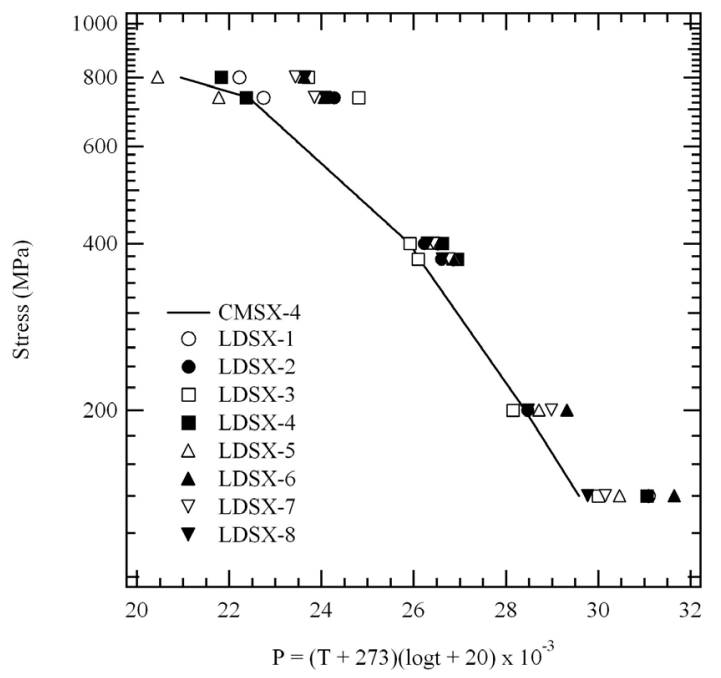

Figure 1 Larson-Miller plot of the time to 1\% creep strain of the LDSX alloys relative to CMSX-4.

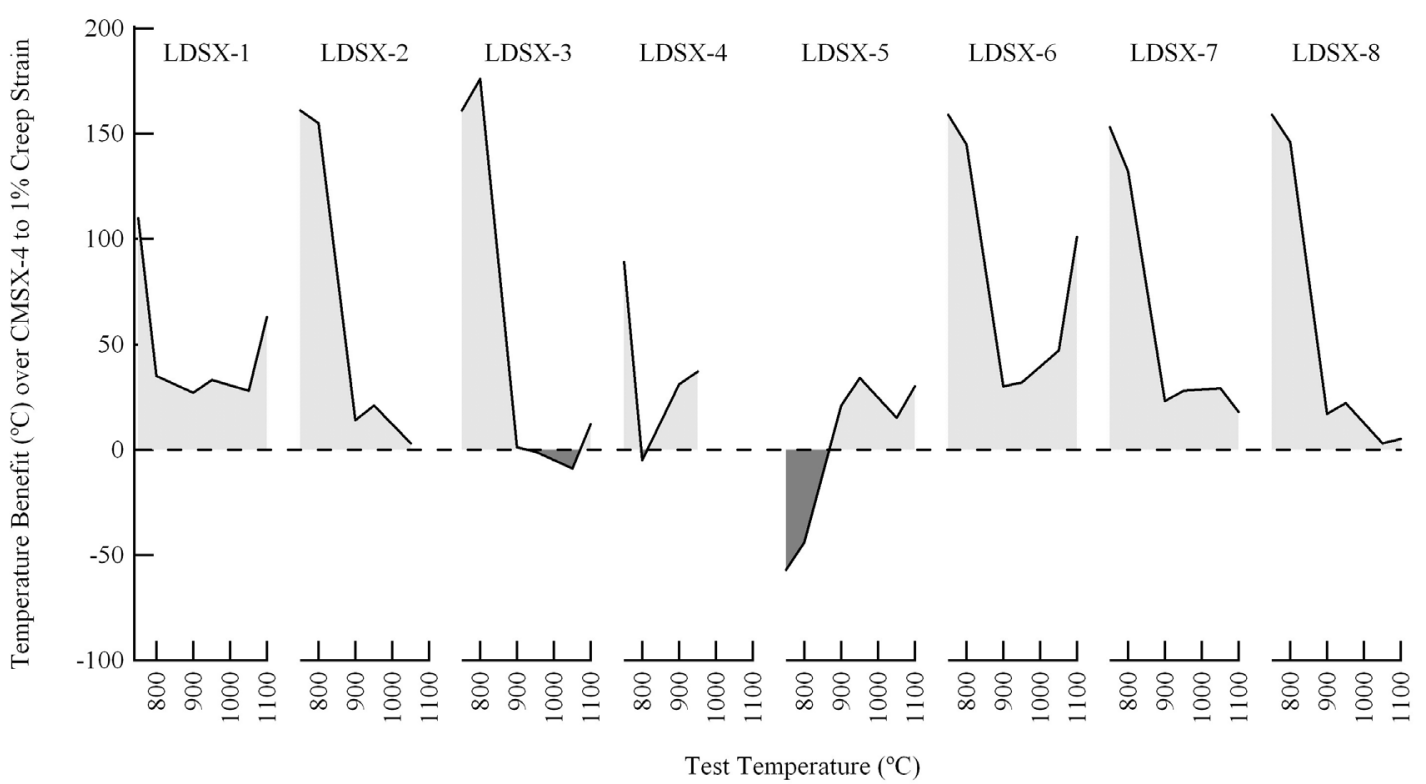

Figure 2 Temperature benefits of the LDSX alloys over CMSX-4 to 1\% creep strain as a function of test temperature.
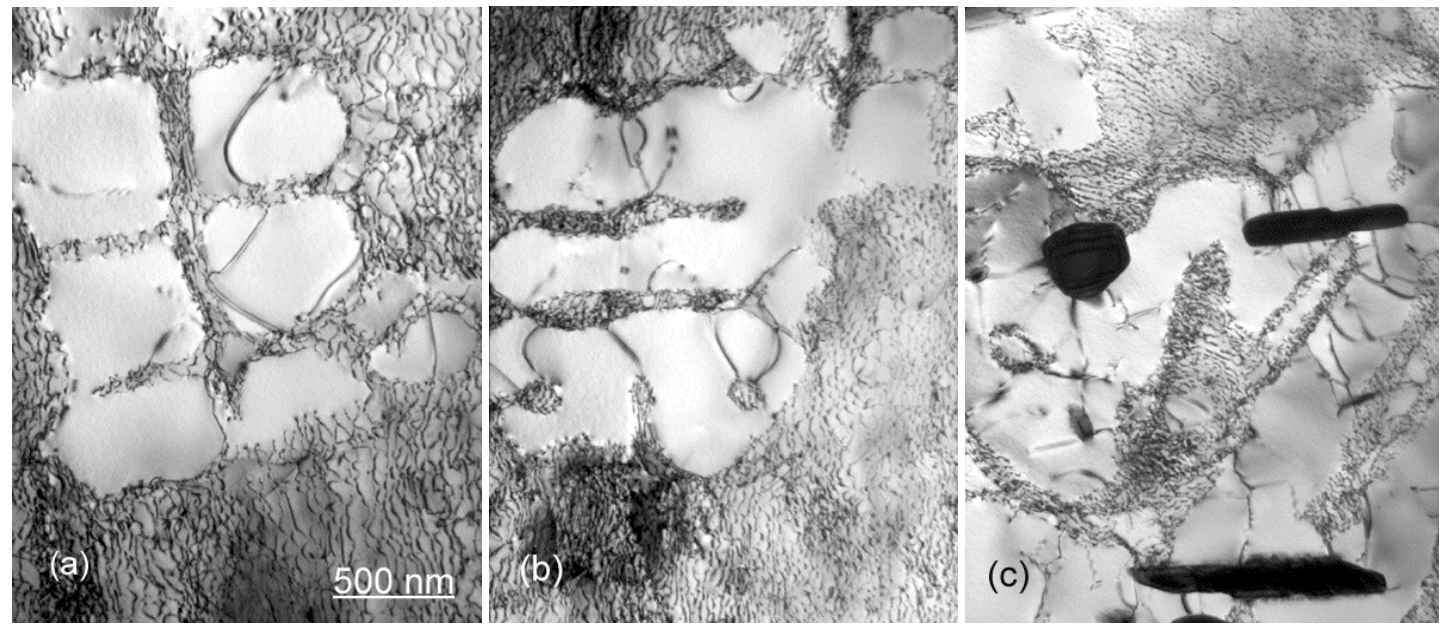

Figure 3 Microstructures of (a) LDSX-1 (b) LDSX-6 and (c) LDSX-8 crept to rupture at $950^{\circ} \mathrm{C} / 375 \mathrm{MPa}$. 
to equilibrate irrespective of chemistry. During intermediate temperature creep, dislocation activity is confined to the $\gamma$ channels because the applied stresses are insufficient to cause shearing of the $\gamma^{\prime}$ precipitates. Hence, to enhance the creep resistance in this regime, Ni-base superalloys are heavily alloyed with Re, W and Mo to preferentially strengthen the $\gamma$ phase. Despite the introduction of $\mathrm{Ru}$ to suppress the precipitation of TCP phases promoted by these additions, there is a finite limit to this approach because of the corresponding increase in negative $\gamma-\gamma^{\prime}$ lattice mismatch, $\delta$, as the lattice parameter of the $\gamma$ matrix $\left(a_{\gamma}\right)$ increases relative to that of the $\gamma^{\prime}$ precipitates $\left(a_{\gamma^{\prime}}\right)$, Equation 1.

$$
\delta=\frac{2\left(a_{\gamma^{\prime}}-a_{\gamma}\right)}{\left(a_{\gamma^{\prime}}+a_{\gamma}\right)}
$$

The misfits of the LDSX alloys at 750 and $950^{\circ} \mathrm{C}$, as calculated by JMatPro, are listed in Table II. The ruptured microstructures of LDSX-1, LDSX-6 and LDSX- 8 at $950{ }^{\circ} \mathrm{C} / 375 \mathrm{MPa}$ in Figure 3 confirm these trends. Sections cut perpendicular to the tensile axis show that the misfit increases in the order LDSX-1, LDSX-6 to LDSX-8, with measured interfacial dislocation network spacings of 35,29 and $25 \mathrm{~nm}$ respectively. Although these trends are consistent with Table II, the lattice misfits calculated from the dislocation network spacings are approximately 1.5 times those predicted by JMatPro.

Table II $\gamma-\gamma^{\prime}$ misfit calculated by JMatPro at 750 and $950^{\circ} \mathrm{C}$.

\begin{tabular}{ccc}
\hline Alloy & $\begin{array}{c}\text { Lattice Misfit at } \\
\mathbf{7 5 0}^{\circ} \mathbf{C} \mathbf{( \% )}\end{array}$ & $\begin{array}{c}\text { Lattice Misfit at } \\
\mathbf{9 5 0}^{\circ} \mathbf{C}(\mathbf{\%})\end{array}$ \\
\hline LDSX-1 & -0.311 & -0.318 \\
LDSX-2 & -0.407 & -0.421 \\
LDSX-3 & -0.448 & -0.456 \\
LDSX-4 & -0.318 & -0.332 \\
LDSX-5 & -0.332 & -0.345 \\
LDSX-6 & -0.365 & -0.372 \\
LDSX-7 & -0.445 & -0.452 \\
LDSX-8 & -0.471 & -0.485 \\
\hline
\end{tabular}

Although a more negative misfit has previously been shown to be beneficial at elevated temperatures [8], plotting of the time to $1 \%$ strain as a function of calculated misfit indicates that, while this also applies at low temperature/high stresses, Figure 4, the reverse is true at intermediate temperatures, Figure 5. The results from the DoE analysis mirror these trends. Statistically, Mo was found to have the largest effect on misfit because it partitions the most strongly of the four factorials to the $\gamma$ phase $[9,10]$. Furthermore, Mo was found to have the only statistically significant contribution on creep. Consistent with misfit, the impact is positive at low temperatures/high stresses and negative at intermediate conditions, Figure 6. Note that the DoE study could not be conducted at high temperatures/low stresses because of incomplete data caused by sample pull out during creep testing. The deleterious effect of Mo is exacerbated at intermediate temperatures because it promotes the precipitation of topologically close-packed (TCP) phases (Figure 3(c)). Microstructural examination suggests Mo is more destabilising than $\mathrm{W}$ and that the potency of $\mathrm{Ru}$ as a TCP suppressant is dependent on the overall concentration of TCP forming elements rather than a sole function of Re content.

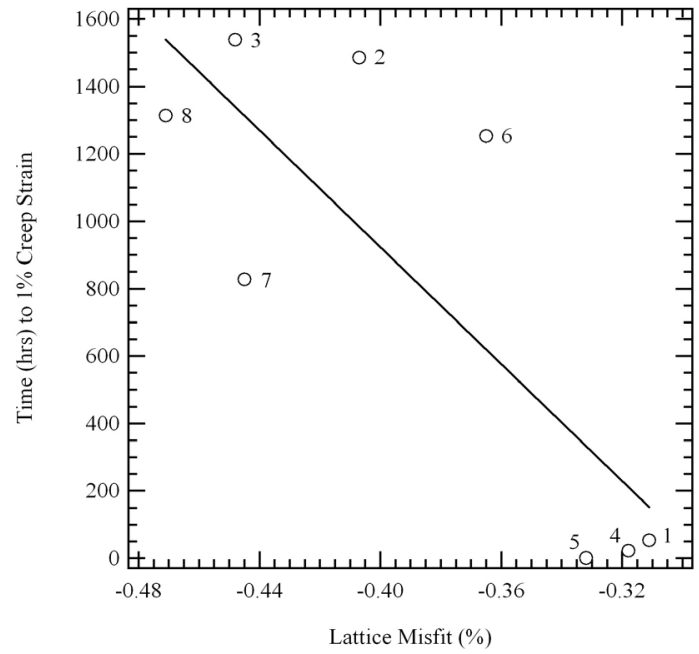

Figure 4 Time to $1 \%$ creep strain as a function of calculated lattice mismatch at $750^{\circ} \mathrm{C} / 800 \mathrm{MPa}$.

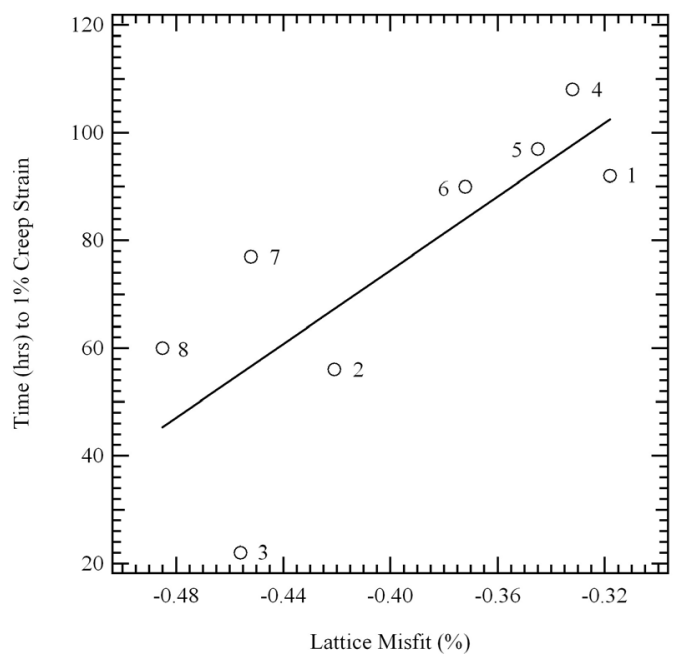

Figure 5 Time to $1 \%$ creep strain as a function of calculated lattice mismatch at $950^{\circ} \mathrm{C} / 375 \mathrm{MPa}$.

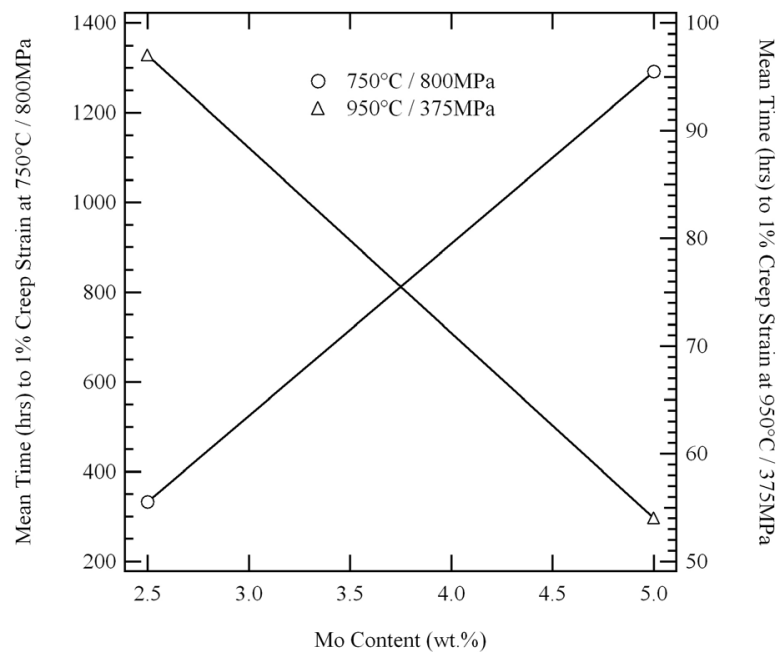

Figure 6 Output from the DoE showing the effect of varying Mo content on the mean time to $1 \%$ creep strain at $750^{\circ} \mathrm{C} / 800 \mathrm{MPa}$ and $950^{\circ} \mathrm{C} / 375 \mathrm{MPa}$. 
The effect of increasing misfit on the rafting behaviour is not trivial. Figure 7 shows the $\gamma-\gamma^{\prime}$ microstructures for three alloys of increasing misfit, namely LDSX-1, LDSX-6 and LDSX-8, in the as heat treated condition, after the initial creep exposure, and following $50 \mathrm{hrs}$ of subsequent isothermal anneal at $950^{\circ} \mathrm{C}$. In the lowest misfit alloy, LDSX-1, conventional rafts form perpendicular to the tensile axis consistent with the negative misfit of the alloy. The sluggish diffusion kinetics in these alloys are apparent from the small pockets of residual $\gamma$ phase trapped in the vertical channels as they close. However, in high negative misfit alloys rafting is promoted in the absence of an applied external stress during the ageing heat treatment. In Figure 7, the fully heat treated structure of the highest misfit alloy, LDSX-8, shows that the $\gamma^{\prime}$ precipitates have aligned into short 'pre-rafts' comprising up to ten precipitates separated by hair-line $\gamma$ channels.

A TEM micrograph of the as-heat-treated LDSX-8 microstructure shows these pre-rafts in greater detail, Figure 8. The $\gamma$ channel widths are non-uniform and the wider channels typically contain secondary cooling $\gamma^{\prime}$. As evident in Figure 7, the number of prerafts in each $<001>$ direction is approximately equal because they form prior to the application of creep strain. This results in approximately one third of the channels becoming too narrow for dislocation penetration during creep and, since they do not experience any relief of misfit, there is no driving force for them to raft perpendicular to the tensile axis as typically observed in a negative misfit alloy. Hence, these channels tend to close during the early stages of creep, irrespective of orientation, and give rise to a spontaneous 'labyrinth' structure: see the as-crept and ascrept plus anneal micrographs of LDSX-8 sectioned parallel to the tensile axis in Figure 7. Note that the rafts parallel to the specimen surface appear as pale patches where they have been sectioned through. The more negative the misfit the earlier the initiation of this microstructure; indeed, for the highest misfit alloy the labyrinth was formed during heat treatment. Consequently, the rafted structure characteristic of high negative misfit alloys is distinct from conventional rafting in that it, firstly, initiates during heat treatment and that it, secondly, comprises rafts in all three $<001>$ directions. The authors refer to this phenomenon as 'labyrinth rafting'.

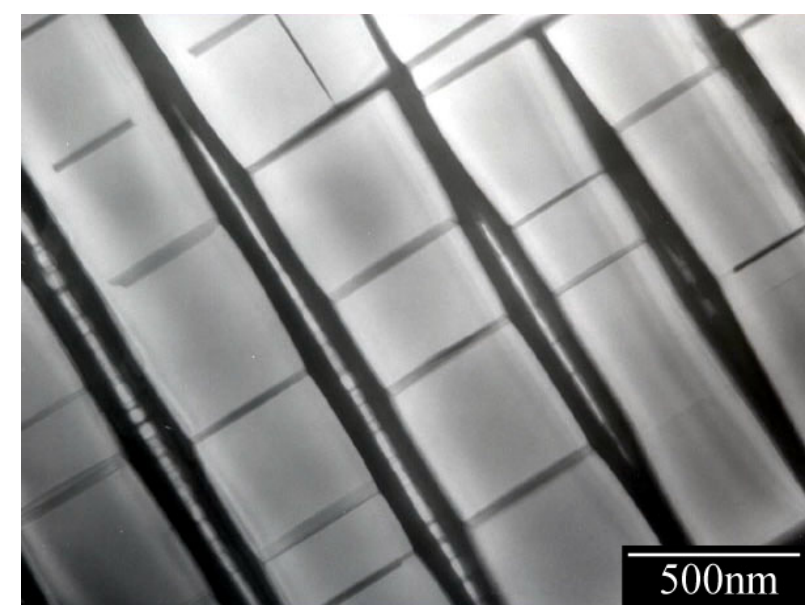

Figure 8 TEM micrograph of LDSX 8 as heat treated showing the formation of 'pre-rafts' in all three $<001>$ directions and the nonuniformity of channel width.
The alloy with intermediate misfit, LDSX-6, exhibits the best creep performance at $950^{\circ} \mathrm{C}$ and also shows the least tendency to raft. This alloy shares some similarities with LDSX-8 in the asheat-treated condition with strong alignment of the precipitates in all three directions, however, it does not share the same tendency to develop into a labyrinth structure. The result is the least amount of rafting of the three alloys studied in detail. This is desirable in the intermediate creep regime because the process of rafting widens the $\gamma$ channels, thereby reducing the Orowan stress which, combined with the ability of the dislocations to cut the $\gamma^{\prime}$ precipitates, leads to rapid breakdown of the rafted structure. Consequently, under these conditions it is preferable to maintain a cuboidal microstructure with a discontinuous $\gamma^{\prime}$ distribution to maximize the Orowan resistance. The labyrinth structure observed in the highest misfit alloy, LDSX-8, is particularly undesirable because the regular junction of wide horizontal and vertical channels effectively reduces the path length required for dislocations to circumvent the rafts oriented perpendicular to the applied stress. This, combined with the greater susceptibility to TCP precipitation, explains the poor creep performance of LDSX8 at intermediate temperatures and stresses. Consequently, this tendency for labyrinth rafting imposes an upper limit on the magnitude of the negative misfit and thus the degree to which the $\gamma$-matrix can be usefully strengthened with refractory elements. This prevents the significant benefits in creep resistance achievable at low temperatures/high stresses and high temperatures/low stresses from being realised at intermediate conditions. LDSX-6 lies right on the limit of this behaviour; of the three alloys investigated in detail it shows the least amount of rafting and also the best creep performance in the intermediate temperature range.

As evident in Figure 4, the correlation between lattice misfit and low temperature $\left(750^{\circ} \mathrm{C}\right)$ creep is not incremental. Instead it appears to involve a threshold: the three 'low misfit' alloys, with calculated misfits below $-0.36 \%$ (LDSX-1, LDSX-4 and LDSX$5)$, exhibit extensive primary creep at $800 \mathrm{MPa}$ with times to $1 \%$ strain well below $100 \mathrm{hrs}$. In contrast, the 'high misfit' alloys, with calculated misfits greater than $-0.36 \%$, all exhibit times to $1 \%$ strain of over $1200 \mathrm{hrs}$. The exception to this is LDSX-7 with a time to $1 \%$ strain of $\sim 800 \mathrm{hrs}$; this discrepancy is attributed to its poor crystallographic orientation. Table III lists the orientations of the tensile axis of each alloy measured as the deviation from the [001] direction, $\theta$, and the rotation from the [001]-[011] axis, $\rho$. In general, the orientations selected were very close to the [001] axis and/or the [001]-[011] symmetry axis and hence would be expected to yield low primary creep. Despite this, comparison of the times to $1 \%$ strain of LDSX-1 and LDSX-6 ( $\sim 50 \mathrm{hrs}$ and $\sim 1250 \mathrm{hrs}$ respectively) whose orientations are almost identical, demonstrates a strong correlation between lattice misfit and the extent of primary creep.

Table III Orientations of the $750^{\circ} \mathrm{C} / 800 \mathrm{MPa}$ creep specimens.

\begin{tabular}{lcc}
\hline Alloy & $\begin{array}{c}\boldsymbol{\theta}\left({ }^{\circ}\right) \\
\text { (Dev. from [001]) }\end{array}$ & $\begin{array}{c}\boldsymbol{\rho}\left({ }^{\circ}\right) \\
\text { (Dev from }[\mathbf{0 0 1}]-[\mathbf{0 1 1}])\end{array}$ \\
\hline LDSX-1 & 2.2 & 6.3 \\
LDSX-2 & 7.9 & 7.8 \\
LDSX-3 & 4.6 & 23.0 \\
LDSX-4 & 2.1 & 5.5 \\
LDSX-5 & 7.0 & 6.1 \\
LDSX-6 & 2.5 & 2.1 \\
LDSX-7 & 9.6 & 30.2 \\
LDSX-8 & 3.8 & 17.0 \\
\hline
\end{tabular}



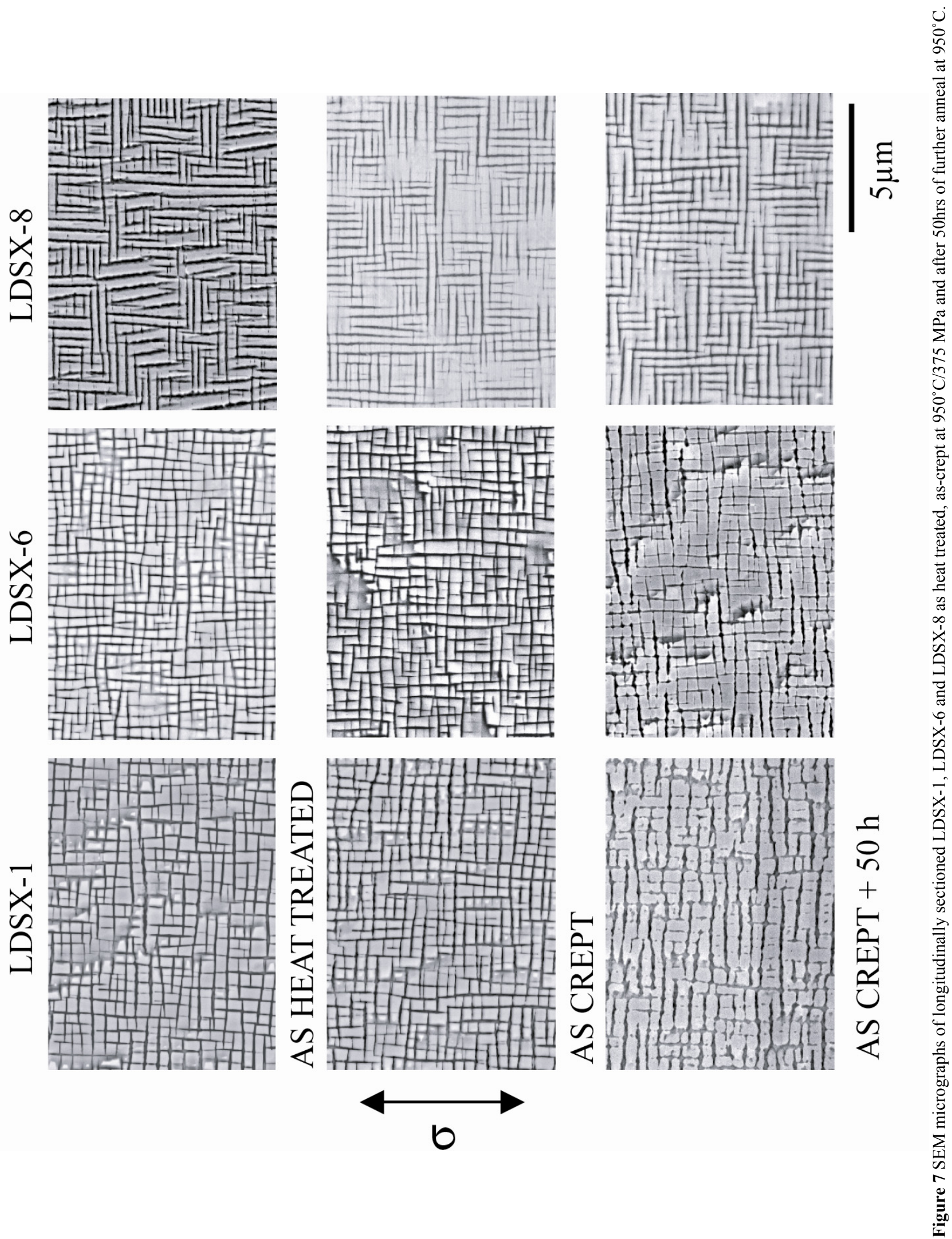
Micrographs of LDSX-1, LDSX-6 and LDSX-8 in Figure 9 tested at $750^{\circ} \mathrm{C} / 800 \mathrm{MPa}$ and interrupted at the start of secondary creep illustrate two striking trends associated with increasing lattice
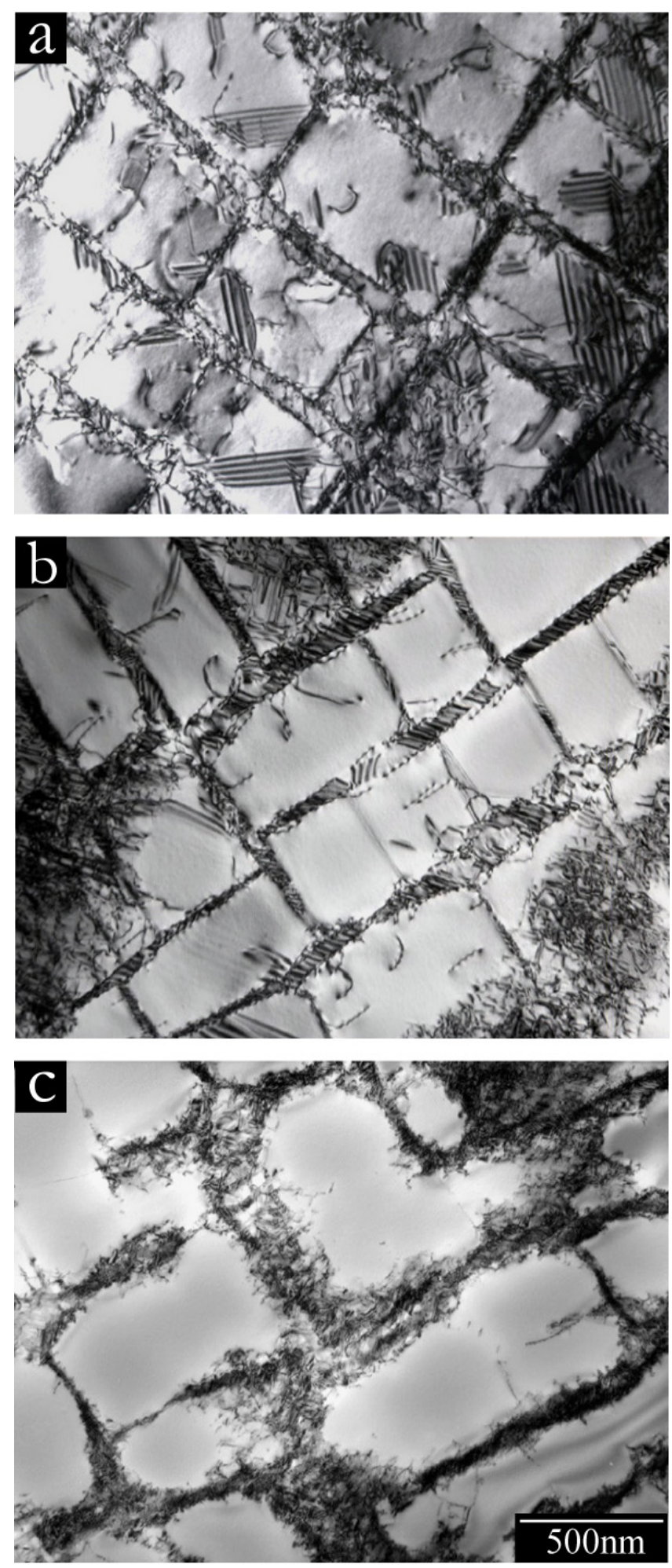

Figure 9 Micrographs sectioned perpendicular to the tensile axis of (a) LDSX-1 (b) LDSX-6 and (c) LDSX-8 tested at $750^{\circ} \mathrm{C} / 800 \mathrm{MPa}$ and interrupted at the start of secondary creep. misfit: first, the density of dislocations in the $\gamma^{\prime}$ decreases and, second, the number of stacking faults in the $\gamma$ channels increases. Dislocation dissociation in the $\gamma$ matrix occurs principally in the vertical (end on) channels while those in the horizontal (in section) channels typically remain as $a / 2<110>$. This is clearly demonstrated in LDSX-6, Figure 9(b), and is consistent with a previous study documenting the beneficial effect of $\mathrm{Ru}$ additions on the $850^{\circ} \mathrm{C}$ creep performance of third generation single crystal superalloys [6]. By promoting the dissociation of dislocations in the vertical $\gamma$ channels, dislocation mobility is inhibited as only the leading partial reaches the adjacent horizontal channel and further propagation would require the activated propagation of the trailing partial through the vertical channel.

As derived in [11], the minimum applied stress along the [001] direction required to completely separate partial dislocations is governed by the stacking fault energy, $\chi$, and the lattice misfit stress, $\sigma_{\mathrm{d}}$, which is negative for a negative misfit alloy, Equation 2 .

$\sigma_{\min }^{[001]}=\frac{6 \sqrt{6}}{b} \cdot \chi+\sigma_{d}$

Therefore, the lower the stacking fault energy and the more negative the misfit the greater the driving force for the formation of stacking faults in the $\gamma$ channels upon the application of an external stress. Several elements, including Cr, Co, Mo, Ti, W, Re and $\mathrm{Ru}$, have been reported to reduce the stacking fault energy of Ni [6,11-14]. Consequently, the increase in the number of $\gamma$ stacking faults from LDSX-1 to LDSX-8 in Figure 8 is a function of the compositional dependence of both the lattice misfit and the $\gamma$ stacking fault energy. However, it is the misfit that governs the relative stresses in the horizontal and vertical $\gamma$ channels and consequently promotes the observed anisotropy in channel dislocation dissociation: the more negative the misfit the greater the barrier to the penetration of $a / 2<110>$ dislocations into the vertical channels. This is illustrated by the crept microstructure of LDSX-6, Figure 9(b), in which the dislocations have only dissociated in the vertical $\gamma$ channels. The corresponding decrease in $\gamma^{\prime}$ dislocation activity suggests that the a/2<110 $>$ dissociation promoted in the vertical $\gamma$ channels by a combination of increasingly negative lattice misfit and decreasing stacking fault energy effectively impedes the distribution of dislocations through the $\gamma$ lattice required to nucleate the stacking fault ribbons that cause extensive primary creep. Indeed, there appears to be a critical negative misfit in this series of alloys at which point primary creep is effectively 'turned off' by this mechanism, Figure 4. Efforts to isolate and quantify the effects of lattice misfit and stacking fault energy on this anomalous primary creep response are currently being pursued.

\section{Low Cycle Fatigue}

The plain LCF data for the LDSX alloys are plotted in Figure 10. All alloys strongly outperform CMSX-4 and, with the exception of three LDSX-1 specimens that possess poor crystallographic orientations, the entire series fall within a relatively narrow scatter band. No consistent trends are evident and none of the four factorials were found to have a statistically significant impact on the LCF life. This suggests that, provided that there is a sufficient Re content and that the alloy is not compromised by instability, then the fatigue performance is more sensitive to microstructure and defect size/population than composition. 


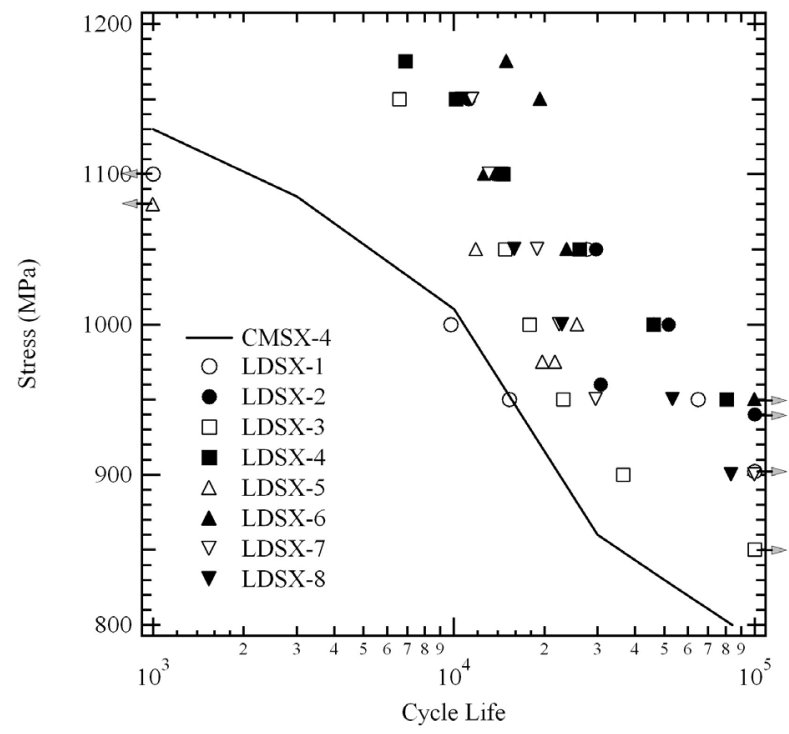

Figure 10 Plain LCF performance of the LDSX alloys.

\section{$\underline{\text { High Temperature Cyclic Oxidation }}$}

Although mechanically the LDSX alloys performed favourably against CMSX-4, no advantage was noted in bare cyclic oxidation in air at $1100^{\circ} \mathrm{C}$, Figure 11 . Indeed, a large spread in oxidation resistance was observed, bounded by the least highly alloyed and best performing variant, LDSX-1, and the most highly alloyed and worst performing variant, LDSX-8.

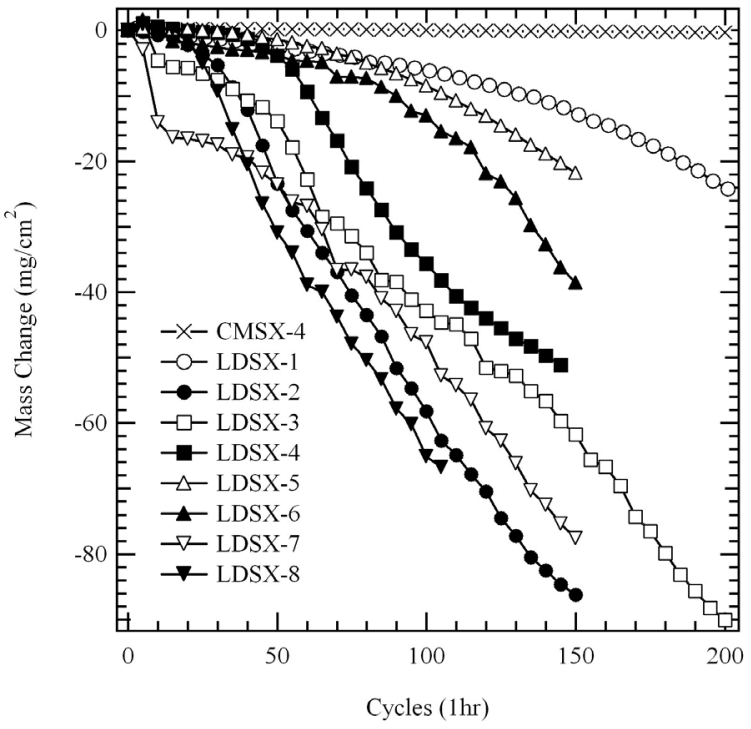

Figure $111100^{\circ} \mathrm{C}$ bare cyclic oxidation resistance of the LDSX alloys.

Microstructural analysis of the oxidised specimens reveals a large variation in the extent of attack around their circumference due to the nature of cyclic attack. However, similar oxide morphologies were observed throughout the alloy series; a typical oxide morphology is shown in Figure 12. It comprises an externally grown nickel oxide layer over an internal layer of nickel aluminium oxide punctuated with a large volume fraction of small, refractory-rich oxides. Between this and the substrate is a thin $(<1 \mu \mathrm{m})$, either continuous or discontinuous, layer of aluminium oxide that grows because the oxygen activity has been lowered by the external oxide layers. Adjacent to this in the substrate is a $\gamma^{\prime}$ depleted zone due to the depletion of aluminium caused by the cyclic spall and re-heal oxidation process. These observations were supported by XRD; all alloys were determined to form the same aggregate oxide species dominated by nickel, nickel aluminium and nickel tantalum oxides combined with nickel tungsten, nickel molybdenum and aluminium oxides in smaller volume fractions.

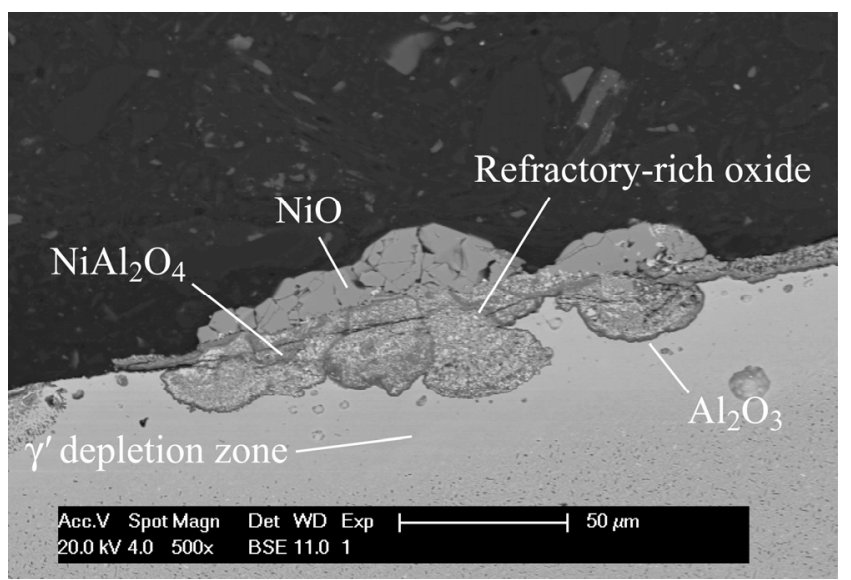

Figure 12 Typical aggregate oxide morphology developed in the LDSX alloys during cyclic oxidation at $1100^{\circ} \mathrm{C}$.

The average mass loss after 120 cycles for each of the alloys was recorded and analysed in the DoE. Both Mo and Co were found to be detrimental (Figure 13), however, statistically the contribution from Mo far outweighs that of Co, explaining $79 \%$ of the variation in mass loss.

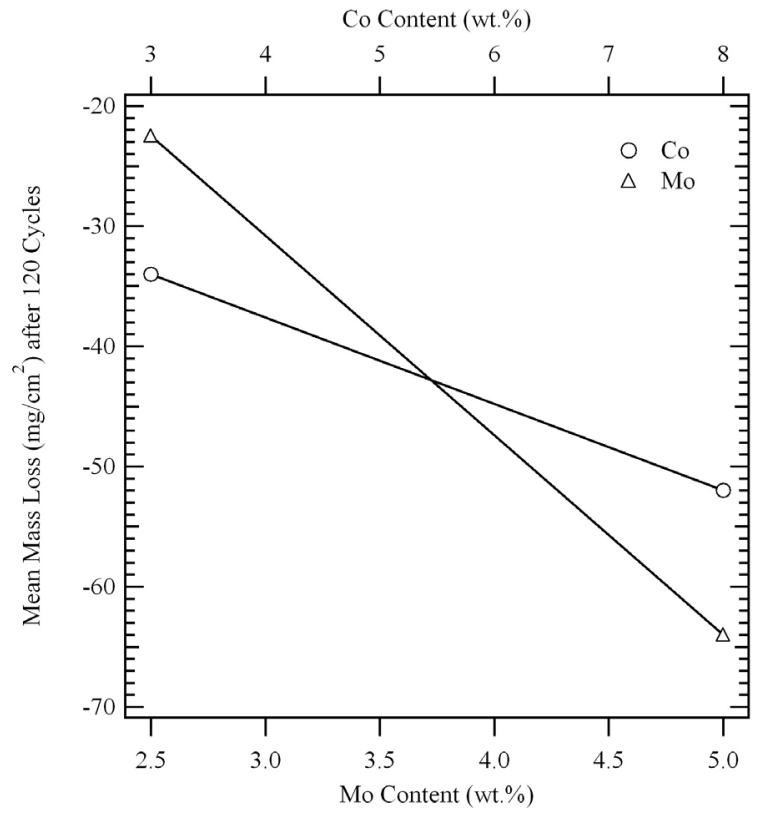

Figure 13 Output from the DoE showing the detrimental effects of increasing Co and Mo contents on the bare $1100^{\circ} \mathrm{C}$ cyclic oxidation resistance of the LDSX alloys. 
To rationalise the negative impact of these two elements on the cyclic oxidation resistance of the LDSX alloys, LDSX-1 and LDSX-2 were subjected to TGA; note LDSX-2 is a higher Moand Co-containing variant of LDSX-1, Table I. As evident in Figure 14, both alloys behaved similarly. Importantly, from the perspective of cyclic oxidation, after approximately a $1 \mathrm{hr}$ isothermal exposure, at which point the first cooling cycle would have taken place in the cyclic oxidation test, both alloys have past the initial transient oxidation stage and exhibit similar oxidation rates, suggesting a similar degree of protection at that point. After $24 \mathrm{hrs}$ both alloys exhibit parabolic growth rates close to that of $\alpha$ alumina, suggesting that is the predominant protective oxide. Subsequent microstructural examination of the test specimens showed the presence of identical multilayer oxides on both alloys comprising an internal alumina layer $(\sim 1 \mu \mathrm{m}$ thick) surrounded by an external layer of nickel aluminium oxide $(\sim 1 \mu \mathrm{m}$ thick) with small nickel tantalum oxide particles sandwiched in between. The majority of the external nickel oxide layer had spalled upon cooling to room temperature. Indeed, regions on both isothermally exposed alloys where the aggregate oxide had spalled and internal oxidation had ensued closely resembled the microstructures of the cyclic oxidation specimens. The presence of $\mathrm{NiAl}_{2} \mathrm{O}_{4}$ above $\mathrm{Al}_{2} \mathrm{O}_{3}$ indicates that these alloys are borderline alumina formers that require the formation of nickel aluminium oxide as a pre-requisite to alumina formation. This explains the poor cyclic oxidation performance of these alloys as compared to an external alumina former, such as CMSX-4. Any subsequent loss of the initial oxide layer would reveal a substrate more depleted in aluminium and therefore less able to re-form a protective oxide scale.

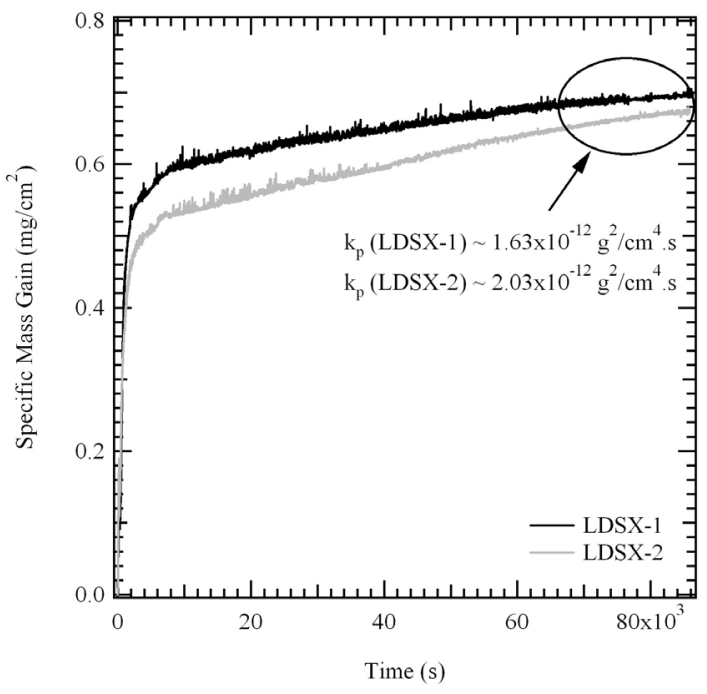

Figure 14 TGA trace of LDSX-1 and LDSX-2 at $1100^{\circ} \mathrm{C}$

Although the work conducted to date does not explain the results from the DoE, the negative impact of Mo on the cyclic oxidation performance of Ni-base superalloys is well documented $[15,16]$. Mo is known to form $\mathrm{MoO}_{3}$ at elevated temperatures [17], indeed, this has been observed as a condensed phase following the high temperature oxidation of Ni-base superalloys [18]. It is therefore postulated that the volatilisation of $\mathrm{MoO}_{3}$ contributes in part to the large mass losses reported in these alloys and/or interferes with the re-healing process, however, direct evidence of this has not yet been confirmed. This is the subject of ongoing research.

\section{TBC Compatibility}

The TBC spallation lives for each alloy are presented in Figure 15. LDSX-6 demonstrates the best compatibility with the existing LCBC/EB-PVD TBC system.

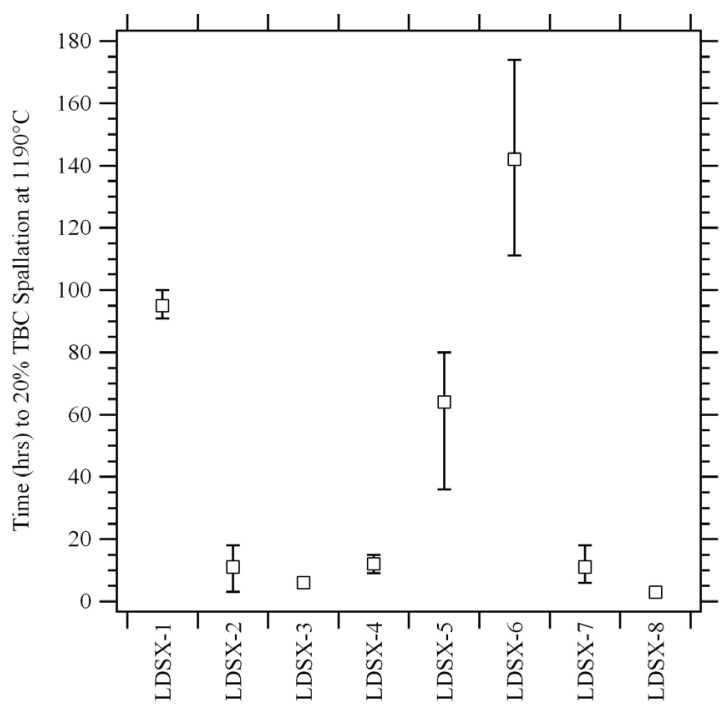

Figure 15 Time in hours to $20 \% \mathrm{TBC}$ spallation at $1190^{\circ} \mathrm{C}$ for the LDSX alloys.

Interestingly, with the exception of LDSX-6, the alloy performance rankings broadly mirror those of cyclic oxidation, Figure 11, with the least highly alloyed variant, LDSX-1, significantly outperforming that most highly alloyed, LDSX-8. Indeed, the results from the DoE analysis of the average time to spallation mimic those of oxidation i.e. both Mo and Co adversely affect TBC compatibility, Figure 16. Combined, Mo and Co explain $58 \%$ of the variation in the mean time to spall.

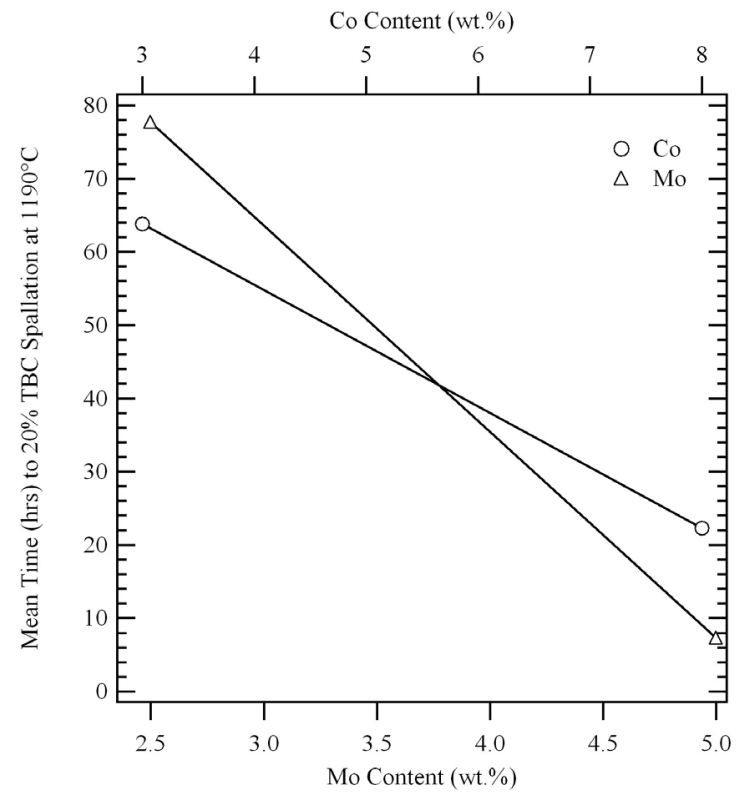

Figure 16 Output from the DoE showing the detrimental effects of increasing $\mathrm{Co}$ and Mo contents on the mean $\mathrm{TBC}$ spallation lives of the LDSX alloys. 
The negative impact of elevated Co contents on TBC compatibility is consistent with previous research [19]. The application of a diffused platinum LCBC into the surface of a $\mathrm{Ni}$ base superalloy creates a platinum-based $\gamma-(\mathrm{Ni}, \mathrm{Pt}) / \gamma^{\prime}-(\mathrm{Ni}, \mathrm{Pt})_{3} \mathrm{Al}$ microstructure, such that a complete $\gamma^{\prime}-(\mathrm{Ni}, \mathrm{Pt})_{3} \mathrm{Al}$ layer is formed in the region below the grit-line. This layer acts as a selective diffusion barrier between the composition of the outer bond coat and that of the bulk substrate. The consumption of aluminium during oxidation in the region above the $\gamma^{\prime}-(\mathrm{Ni}, \mathrm{Pt}) 3 \mathrm{Al}$ layer results in the concentration, and eventual incorporation, of Co into the thermally-grown oxide (TGO). The failure of the TBC was found to be initiated at the substrate/oxide interface and resulted from cobalt interrupting the continued formation of the TGO layer. Further work is required to establish whether the mechanism by which increasing Mo additions adversely impact TBC compatibility is equivalent to, or indeed synergistic with, that of Co.

\section{Summary and Conclusions}

The eight $\mathrm{Ru}$-containing single crystal Ni-base superalloys evaluated in this study deliver significant benefits over CMSX-4 mechanically. However, all the alloys are borderline alumina formers, requiring the formation of $\mathrm{NiAl}_{2} \mathrm{O}_{4}$ as a pre-requisite to $\mathrm{Al}_{2} \mathrm{O}_{3}$ formation. Consequently, none of the LDSX alloys provide the combination of mechanical and environmental properties demanded by the next generation of gas turbine engines.

Of the four factorials in the DoE, only Mo and Co were found to have a statistically significant impact on the properties investigated:

- Increasing Mo contents enhance the creep performance at low temperatures/high stresses and degrade the creep performance at intermediate temperatures and stresses.

- Increasing Mo and Co contents degrade the bare alloy cyclic oxidation resistance at $1100^{\circ} \mathrm{C}$.

- Increasing Mo and Co contents degrade the TBC spallation resistance at $1190^{\circ} \mathrm{C}$.

Two new phenomena promoted by high negative lattice misfit have been reported. First, a negative misfit threshold above which primary creep is effectively 'turned off' under low temperature/high stress conditions. Second, 'labyrinth rafting' in the intermediate to high temperature creep regimes resulting in the formation of approximately equal numbers of rafts in all three $<001>$ directions irrespective of the direction of the applied stress. This structure is undesirable because it provides a maze of wide and interconnected horizontal and vertical $\gamma$ channels through which the dislocations can propagate. This tendency for labyrinth rafting, therefore, imposes an upper limit on the magnitude of the negative misfit and thus the degree to which the $\gamma$-matrix can be usefully strengthened with refractory elements. LDSX-6 was determined to have the optimum amount of negative lattice misfit i.e. above the threshold required to suppress primary creep and below that found to induce spontaneous labyrinth rafting.

\section{Acknowledgements}

The authors gratefully acknowledge Rolls-Royce plc.. the Engineering and Physical Sciences Research Council (EPSRC) and the Ministry of Defence (MoD) for the provision of material and funding.
The authors would like to highlight the significant technical and experimental contributions of Dr L. Zhang, Dr H.T. Pang and Miss J. Ang of the University of Cambridge and also wish to extend their gratitude to Dr R.W. Broomfield, Dr C.N. Jones, Dr R. Jones and Mr P.C. Lord of Rolls-Royce plc. and Dr H.J. Stone of the University of Cambridge and Mr I.M. Edmonds of the University of Birmingham for their invaluable input.

\section{References}

1. K.S. O'Hara, W.S. Walston, E.W. Ross, R. Darolia, US Patent 5,482,789 (1996).

2. A. Sato, H. Harada, T. Yokokawa, T, Murakumo, Y. Koizumi, T. Kobayashi, H. Imai, Scripta Mater. 54(9) (2006) $1679-1684$

3. A.C. Yeh, S. Tin, Metall. Mater. Trans. A. 37(9) (2006) 2621-2631.

4. R.A. Hobbs, L. Zhang, C.M.F. Rae, S. Tin, Metall. Mater. Trans. A, 39(5) (2008) 1014-1025.

5. A.C. Yeh, C.M.F. Rae, S. Tin, Superalloys 2004, eds. K.A. Green et al., TMS, Warrendale, PA, 2004, pp. 677-686.

6. R.A. Hobbs, L. Zhang, C.M.F. Rae, S. Tin, Mater. Sci. Eng. A. (2008) In press: doi:10.1016/j.msea.2007.12.045.

7. N. Matan, D.C. Cox, C.M.F. Rae, R.C. Reed, Acta Mater. 47 (1999) 2031-2045.

8. J.X. Zhang, T. Murakumo, H. Harada, Y. Koizumi, Scripta Mater. 48 (2003) 287-293.

9. K.E. Yoon, D. Isheim, R.D. Noebe, D.N. Seidman, Interface Sci. 9 (2001) 249-255.

10. R.C. Reed, A.C. Yeh, S. Tin, S.S. Babu, M.K. Miller, Scripta Mater. 51 (2004) 327-331.

11. S. Ma, L. Carroll, T.M. Pollock, Acta Mater. 55 (2007) 58025812 .

12. P.S. Lotval, O.H. Nestor, Trans. AIME. 245 (1969) 1275.

13. B.E. Beeston, L.K. France, J. Inst. Metals. 96 (1968) 105.

14. N. Tierny, N.J. Grant, Metall. Trans. A. 13 (1982) 1827.

15. J.L. Gonzalez Carrasco, P. Adeva, M. Aballe, Oxidation of Metals. 33(1-2) (1990) 1-17.

16. R. Hashizume, A. Yoshinari, T. Kiyono, Y. Murata, M. Morinaga, Superalloys 2004, eds. K.A. Green et al.,TMS, Warrendale, PA, 2004, pp. 53-62.

17. R. Speiser, G.R. St. Pierre, The Science and Technology of Tungsten, Tantalum, Molybdenum, Niobium and Their Alloys, Pergamon Press, New York, 1964 pp 289-330.

18. J.A. Goebel, F.S. Pettit, G.W. Goward, Metall. Trans. 4 (1973) 261-278.

19. M.S. Hook, Ph.D. Thesis, The University of Cambridge (2004). 